\title{
Los artículos "Café Perec", de EnRIQue Vila-Matas, ¿UNA PALESTRA EN EL ESPACIO PÚBLICO ACTUAL?
}

\author{
Isabel Verdú Arnal \\ (Universitat de Barcelona)
}

\begin{abstract}
El intelectual, en mi entender, ha venido al mundo nada más que para esforzarse en perseguir la verdad, y una vez encontrada lanzarla acaloradamente al viento. (José Ortega y Gasset, La rebelión de las masas)
\end{abstract}

\section{Introducción}

Enrique Vila-Matas ha acabado constituyendo una figura indispensable en el panorama literario contemporáneo, si bien el reconocimiento de su obra ha sido tardío, especialmente en la Península. Su obra narrativa llevaba casi tres décadas en marcha cuando obtuvo el Premio Internacional Rómulo Gallegos en Venezuela (2001), así como el Premio Ciudad de Barcelona. A partir de aquí ha ido afianzándose su lugar en la contemporaneidad, obteniendo premios dentro y fuera de España: Premio Formentor de las Letras (España, 2014), Premio Fil de Literatura (México 2015), Premi Nacional de Cultura de la Generalitat (2016). A lo largo de su trayectoria atípica se le ha llamado "El príncipe de los shandys" [Domínguez 2007], "el notario de lo raro" [Martínez de Pisón 2007] o el "maestro de la literatura y la metaliteratura" [Pozuelo Yvancos 2017]. Pudiéramos pensar, pues, que se trata de un autor radicalmente situado en lo excéntrico, alejado de los circuitos de la contemporaneidad. Máxime teniendo en cuenta que los estudios que se le han dedicado hasta el momento normalmente se han centrado en la condición lúdica, posmoderna o metaliteraria de su arte. ${ }^{1}$

\footnotetext{
${ }^{1}$ La primera tesis defendida sobre Vila-Matas fue en El universo literario de Enrique Vila-Matas, por Critina Oñoro Otero en la Universidad Complutense de Madrid en 2007, centrada en la condición postmoderna de su arte; trabajo que fue luego convertido en el libro Juegos, ficciones, silencios [2015]. Otras tesis publicadas en los siguientes años han sido Entre lugares de la modernidad. La trilogía meta-literaria de Vila-Matas como ejemplo de una escritura intersticial, defendida por Olalla Castro Hernández en la Universidad de Granada (2014) o Placer e irritación del lector ante la obra de Vila-Matas, defendida por Julia González de Carcereny en la Universidad de Saint Gallen en 2014 y que después tomó la forma del libro Releyendo a Vila-Matas: placer e irritación [2016].
} 
Ahora bien, existe también otro Vila-Matas menos comentado, que es precisamente el de la reflexión sobre el presente político ${ }^{2}$. Dicha cuestión ha ido apareciendo de manera tangencial en su obra narrativa desde los orígenes (como los referentes a la guerra civil española y los excesos del catolicismo en su primera novela, Mujer en el espejo contemplando el paisaje, escrita aún en tiempos de Franco, en 1973), hasta las últimas novelas, donde podemos hallar la preocupación por Europa (Kassel no invita a la lógica, 2014) o las menciones a la crisis política y económica actual (en Mac y su contratiempo, 2017). Sin embargo, es en la producción articulística donde la presencia de la realidad cobra unos tintes cada vez más precisos. Desde sus inicios, Vila-Matas se ha caracterizado por una escritura ensayística donde la preocupación por el cine o la literatura se entrevera de menciones críticas al presente político. Así, en uno de sus primeros artículos en Fotogramas, adjuntaba el siguiente comentario final a una reseña sobre cine nuevo francés: "Una vez más, la crítica al sistema por los caminos de la imaginación ha conseguido dar los frutos apetecidos" [1968]. Por otro lado, el artículo "Espiando a los artistas", publicado en 1993 y recogido en El traje de los domingos, relata un gesto de Miró "de absoluta, de increíble libertad" que le impacta para siempre [2006: 24]. Y en "La gallina robada (Cuento de Navidad)", publicado originariamente en 1994, refleja irónicamente el contraste entre Dalí y la España franquista, y finaliza así: "en aquella España de gallinas robadas por familias limpias y pobres como la mía, que vivía sin estufas, pero feliz entre tantos melones y hostias consagradas" [2006: 14].

De todos modos, es en los artículos Café Perec, publicados en El País desde el 2010 hasta la actualidad y que ya alcanzan el número de 178 , donde mejor podremos rastrear la huella de la preocupación política.

\section{"Café Perec", ¿una postura política e intelectual?}

Huelga decir que en el germen de los microensayos que se publican bajo el epígrafe "Café Perec" se halla un artículo de Enrique Vila-Matas de 2008 así titulado, que se erige en homenaje a Georges Perec y su literatura de la observación, lo irrisorio y el juego, "lo que generalmente no se anota, lo que se nota, lo que no tiene importancia, lo que pasa cuando no pasa nada, salvo tiempo, gente,

\footnotetext{
${ }^{2}$ Cuestión que ha apuntado Jordi Gracia en una ocasión [2015] y que Alfredo Aranda ha estudiado parcialmente en su tesis sobre la textura del ensayo en Vila-Matas, aunque más centrada en el ensayo literario: La escritura articulística y ensayística de Enrique Vila-Matas: la crítica de un escritor [2017].
} 
autos y nubes". Esa referencia perecquiana a Tentativa de agotar un lugar parisino acaba llevando al escritor a la siguiente reflexión propia:

¿Y qué sucede cuando no ocurre nada? Que termina uno a veces por acordarse de los orígenes de su fascinación por las tramas no convencionales y recuerda cuando descubrió que se podían construir libros libres, de estructuras inéditas, con asociaciones y cavilaciones en torno a centros ausentes...

Y efectivamente los artículos Café Perec, que retoman implícitamente la figura del Café literario como icono del diálogo y la modernidad [Martí 2007], se gestan a partir de asociaciones de ideas muy libres; aunque el eje central de los artículos sea la literatura, también hay alusión a sucesos políticos contemporáneos, a veces de forma muy secundaria, pero otras trenzando auténticas analogías entre literatura y contemporaneidad. Así, en "Si no fuera por la crisis" [2011] alude a la crisis económica; el motivo de las urnas se da en "El gran fracasista" [2012] o en "La noche de Europa" [2014]. La corrupción política salpica textos como "Nuestra salvación" [2013] y el disgusto por la Ley Wert configura el punto de partida de "Dirección animal" [2013]. Nadie queda a salvo aquí: ni el partido Podemos ni El congreso de los Diputados, ni las elecciones americanas ni el movimiento independentista catalán. No son estos los únicos motivos en Café Perec, cuyo epicentro se articula en torno a lecturas, películas y apología de la cultura en general. Sin embargo, las menciones políticas son explícitas a la vez que cubiertas por un velo de ambigüedad.

¿Pueden considerarse sus palabras un discurso intelectual? Atendiendo a la etimología de la palabra "intelectual", que procede de "intelligere" ("comprender, entender") y a su vez deriva de "legere", esto es "coger, escoger", la misión del intelectual ha de ser leer y entender la realidad; para después escoger una postura y sostenerla de manera pública. Sin embargo, aunque en Vila-Matas haya lectura e interpretación de la realidad, el posicionamiento no aparece muy explícito. Difícilmente se tratará del intelectual comprometido canónico tal y como lo conocemos, cuya aparición coincide con el nacimiento del capitalismo y la separación de poderes, y por tanto la posibilidad de criticar el orden establecido, así como con el auge del ensayo como género y el incremento del público lector. Este intelectual activista que ejerce de contrapunto al poder establecido se vería representado en la figura de Zola primero y su J'accuse, y en la de Sartre después, en su versión más politizada, con el intelectual engagé. Esa misma línea parecen tener aún en cuenta Bourdieu [2012] cuando 
reclama la asunción de la "función pública" de los intelectuales, o Traverso [2013] cuando exige que el intelectual mantenga cierta capacidad para el compromiso e incluso la utopía.

Pero hay otras posturas, herederas de la despolitización del sesenta y ocho y de la tradición vanguardista; posturas más afines a Vila-Matas, tanto por contexto generacional como por contexto cultural: las de Barthes y Blanchot, que son algunos de los autores más citados por él. Así, recordemos a Roland Barthes que distinguía el "escritor" (o "écrivain") del "intelectual" o "escribiente" ("écrivant"). El escritor debe soportar la literatura como "un engagement manqué" [Barthes 2002: 407]; esto es, ha de soportar la paradoja del acto literario, donde la palabra nunca llega a nombrar con exactitud aquello que desea decir, a diferencia del intelectual, para quien lo principal es el uso del lenguaje como vehículo de comunicación. Según Barthes, puede producirse una identidad "bastarda" entre escritor o intelectual, pero estas identidades nunca coincidirán al cien por cien. En el caso de VilaMatas aunque podamos tildar su postura de intelectual al comunicar algunas ideas al lector, lo hace dentro de una ambigüedad esencial y siempre dentro de un universo de juego literario, donde la política aparece, sí, pero de forma tangencial y azarosa, como un autobús pasando por la plaza Sant Sulpice a ojos de Georges Perec.

\section{Un reto al lector: mecanismos de ambigüedad y plurisignificación textual}

Pasando a un análisis pragmático del texto: el espacio que se comparte con el lector (Café Perec) pertenece al diario El País, así que predispone a una reflexión sobre actualidad, si bien ubicado en una sección propia de Vila-Matas y dentro del apartado de cultura. El epígrafe Café Perec enmarca la lectura dentro de un contexto que incita al intercambio abierto de ideas, e imbrica el homenaje a un autor, Georges Perec, perteneciente no a un grupo de escritores comprometidos sino al Oulipo, un grupo de experimentación literaria acuñado en los sesenta franceses. Por tanto el marco pragmático de los artículos plantea un espacio de participación al lector, pero dentro del registro literario, apelando antes que nada a sus facultades cognitivas y emocionales. puesto que, tal y como ha explicado la pragmática literaria, la participación literaria es alta pero "desinteresada"; se da "cognitiva e imaginativa únicamente, un acto de la mente y del corazón" y "sus consecuencias están suspendidas" [Ohmann 1999: 48-49]. 
Tomemos como ejemplo diversos artículos donde surge el tema del nacionalismo; cuestión respecto a la que Vila-Matas siempre se ha mostrado muy crítico, y como Joyce, en la línea de un "universalismo cultural" [Saldaña 2012] y un "discurso transnacional" [González de Canales 2016:109]

Para empezar, "Del amor" [2012] plantea el tema del amor como pasión, a resultas de la novela El gran Gatsby. Y sin embargo, se arranca con esta pregunta desconcertante: "¿Y qué decir del amor por un país extranjero? Parece una especie de nacionalismo al revés: lo Distinto encanta, lo idéntico aburre, lo Otro exalta..." Dicha sentencia, en un texto publicado un día 24 de septiembre, trece días después de la Diada de Catalunya, es si más no, sospechosa. La antítesis entre los verbos positivos "Encantar" y "exaltar" respecto a "aburrir" seguidos de adjetivos valorativos marca una suerte de quiasmo implícito en contraposición a los términos entusiastas por la propia nación. Un poco más abajo, leemos una sentencia donde la ambigüedad entre semántica amorosa y política es total: "El amor, está claro, es el único sentimiento que introduce la idea del otro, el único que nos permite escapar de la trampa de la identidad propia, de lo neuróticamente abocado a uno mismo."

Unos meses después, se publica "Nuestra salvación" [2013] donde compara el día de la marmota con Rajoy negando "tener algo que ver con la cuenta de Bárcenas". Después de la breve alusión a la corrupción política, irrumpe: "¿Y a qué suena el día de la marmota? A tedio. Y el sábado me sonó a nación. ¿Y qué es una nación? "Es la misma gente viviendo en el mismo sitio (Leopold Bloom en Ulises)". De nuevo en pocas líneas queda desarmada toda idea de nacionalismo, pero apuntalada no por idea política alguna sino por la mención a James Joyce: la cultura y lo transnacional ejerciendo de sostén cuando las certezas se derrumban.

Por otro lado, en el artículo "Propuesta de cambio" [2013] se plantea el peligro de usar las "grandes verdades"; y hacer "una política que embauque a las masas y acabe siendo desaforada y cause estragos" como sucedió en Alemania, en oposición a las "modestas verdades" para lograr una "convivencia libre y pacífica". Después de la solemne advertencia, aflora la ligereza de las ideas artísticas, y en su ensoñación los políticos se convierten "discretos y altruistas" y son sustituidos "repentinos y gentiles atisbos de cultura" con todo tipo de invenciones artísticas. Por añadidura, la denuncia a actitudes y situaciones no desemboca en apología de solución ideológica alguna, sino que se limita a un aletazo de arenga o mofa antipolítica.

En "La manía de caernos del mundo" [2015] los extremos se ponen en tela de juicio y se aboga por el centro como un lugar viable, no solo político sino existencialmente hablando. Los 
extremos son relacionados con "esa tendencia a caer en abismos y demás vías muertas del pasado", para después incrementar aún más la connotación negativa con adjetivos como "tarada manía de caernos del mundo" o "deslizarnos por rancios márgenes". Al final del texto se alude a los coetáneos "surgiendo aficionados a ese baile tremendamente local" donde realizan "mil cabriolas ridículas" para desembocar en unas imágenes tan sorprendentes como alucinatorias: "A un lado y al otro, tocándose ambos extremos, cada vez hay más adictos a lanzarnos por despeñaderos de segunda fila, cada vez más vendedores de humo revolucionario por un lado y de pavorosas atmósferas de atardeceres zulús por el otro."

Asimismo, el artículo "Encerrados con un solo tedio" [2017] retoma la palabra "tedio" que usaba en otras ocasiones en referencia a la nación española. La abertura del texto trata sobre el aburrimiento como lento paso del tiempo, tanto en su recuerdo de la mili en Melilla como en el libro Tiempo de Safranski, y luego en el relato de Buzati El desierto de los tártaros. En el más breve párrafo central acaba explicitando lo siguiente:

\footnotetext{
En una atmósfera parecida se asienta, cada día más, el muy kafkiano procesismo de Cataluña. Allí, dos veteranos partidos, enrocados en una tenaz repetición de un mismo estado de tedio -ahora cae una gota y pasa un segundo de nuevo, y ahora cae otra y de nuevo un referéndum- , han encontrado en la insistencia en un tema único un método para no perder nunca las elecciones.
}

Dicho lo cual parece resta importancia al aserto al hacer un brusco viraje que nos devuelve de nuevo al ámbito cultural: "Pero quizás la versión más perversa de encierro y síndrome de Drogo se halle en Ni le ciel ni la terre, un film de Clément Cogitore..." hasta acabar así: "en medio de semejante desconcierto, Cogitore va dibujando una parábola aterradora sobre la soledad en el universo."

Destaquemos también el artículo "35 años de Glenn Gould" [2017], que aparece el 3 de octubre, justo dos días después del conocido referéndum 1-O por la independencia en Catalunya ${ }^{3}$, ocasión en la que era harto peliagudo hacer mención del tema sin caer en ninguna de las polaridades independentista o antiindependentista. Vila-Matas opta por la mención a la efeméride de la muerte del pianista Glenn Gould y a unas alusiones laterales a cuanto estaba sucediendo. Ahora bien, algo

\footnotetext{
${ }^{3}$ El Referéndum de autodeterminación en Catalunya del 1-10-2017 se llevó adelante promovido desde la Generalitat de Catalunya, y a pesar de que el Tribunal Constitucional lo hubiera declarado ilegal. Con una moderada participación, obtuvo la victoria el sí, aunque sin las condiciones normativas necesarias, y supuso una intervención de la policía estatal que se saldó con algunos heridos, hechos que provocaron una profunda división en la opinión pública, sobre la oportunidad o no de dicho referéndum. El 10 de octubre el gobierno catalán decidió proclamar la DUI (Declaración Unilateral de Independencia) aunque con la salvedad de mantener sus efectos suspendidos mientras esperaban alcanzar una solución acordada con el gobierno español. El presidente Rajoy aguardó una rectificación del presidente catalán Puigdemont y al no ser así finalmente el 21 de diciembre decidió aplicar el artículo 155 mediante el cual la autonomía de Catalunya quedaba intervenida y después convocó elecciones para el 21-12-2017 https://es.wikipedia.org/wiki/Refer\%C3\%A9ndum_de_independencia_de_ Catalu\%C3\%B1a_de_2017)
} 
deja claro desde el principio: "La gravísima e injustificable violencia del domingo en Cataluña me impedía más que nunca olvidarme de dónde estaba, y menos aún, como un Kafka cualquiera, irme por la tarde a nadar." Una vez asentada sin ambages su denuncia de la acción policial, desmarcándose por tanto de toda connivencia con el gobierno central y su represión violenta del referéndum, aprovecha para decir, al hilo de Hambre De Knut Hamsun, "suelo ser partidario de los jóvenes de comportamiento inestable, torpe y tímido, amigo de los que no saben moverse con soltura por la vida real.". Y al final recuerda unas palabras del pianista haciendo mención a "que lo que sucedía entre su mano izquierda y su mano derecha no era de la incumbencia de nadie". "35 años sin Glenn Gould", sin ser un artículo político, deja las bases de una moral política clara: la que no aboga por la violencia ni tampoco por ningún extremismo, sino que defiende el derecho a la indefinición y lo errático, como hacen sus héroes literarios.

Por último, "Viaje a Bastia" [2017], del pasado 16 de octubre, subraya de manera irrisoria la capacidad de cualquier texto de ser leído en doble sentido respecto a la actualidad. Así, si bien muestra un gran hastío respecto a la llamada perifrástica e hiperbólicamente "pulsión de una sola cuerda" o "pulsión monotemática que, por tierra, mar y televisión, recorre el país", abre un muestrario de conexiones indirectas del texto respecto al tema catalán en clave humorística. El léxico sobre actos políticos ha pasado a actos textuales, de significado compartido entre autor y lector, cuando advierte que el artículo ha sido activado "en diferido" (que nos trae ecos de la declaración unilateral de independencia suspendida) o que el texto puede ser "intervenido" por los lectores y leído en clave "crisis catalana" (haciendo alusión a la amenaza de intervención estatal en la Autonomía catalana que pendía en ese momento). Y llega a afirmar que cualquier tema podría conectarse con la misma cuestión, hasta el festival de terror de Sitges o algún libro de editorial Acantilado. El Vila-Matas del texto se desplaza a Córcega, pero allí no logra olvidar el tema cuando lee la necesidad de los corsos de "identificarse con uno o varios grupos a través de los cuales podían sentir que existían: familia, clan, pueblo..." El texto acaba cerrándose doblemente con Kafka mediante su famosa frase "Por la tarde fui a nadar" y también con la mención al relato donde el ratón se dirige hacia la trampa mortal sin haber sido capaz de cambiar de dirección. "La trampa ha sido siempre lo que no se ve-dice Vila-Matas- La trampa es la realidad."

Podríamos sospechar que el modo abiertamente elíptico con el que Vila-Matas trata el tema de la crisis catalana tiene que ver con lo susceptible del tema en sociedad. Sin embargo, las estrategias 
usadas son las mismas que en otros artículos, donde se muestran y a la vez se ocultan otros contenidos políticos.

Así, las estructuras lingüísticas nos acercan a un tipo de discurso donde lo importante no es la factualidad que se halla tras las referencias del texto, ni la verdad última del enunciado, sino el esfuerzo de comprensión requerido en el lector, al que se le trata de sorprender y evitar cualquier tipo de adormecimiento interpretativo. Lo real y lo literario se acaba poniendo al mismo nivel de muchas maneras: por un lado, la situación enunciativa resulta ambigua. A menudo se parte de un espacio determinado, un avión, o un recuerdo, o una ciudad, para catapultarnos a diversos espacios de la actualidad, la literatura o la imaginación. Así, "Acuérdate de desconfiar" [2012] finaliza de esta guisa: "Nos hallábamos en Florencia y, por tanto, en uno de los centros del mundo. ¿O estábamos en un bosque perdido, en las afueras de Kassel, en las afueras de la antaño poderosa Alemania?" También los referentes temporales ejecutan acrobacias de lo disperso a lo inespecífico, como en "Conjuras invisibles" [2010] donde se pasa por 1936 en Tossa de Mar y el crack 29 para desembocar en "ayer" y un deseo de conjurarse y "ocultarlo todo en la medianoche".

En cuanto al sujeto textual, oscila entre el yo, el nosotros y la tercera persona. En "Súbita aparición de Nunes" [2016] leemos: 'Concluía el año de 1970 y trescientos 'intelectuales' se habían encerrado en Montserrat contra el gobierno franquista por el Proceso de Burgos." Y súbitamente se incluye el sujeto textual dentro del enunciado: "Acabábamos ${ }^{4}$ de decidir que terminaba el encierro de dos días...", de manera que el sujeto textual a la vez parece estar y no dentro de los hechos relatados, cosa que difumina al mismo tiempo la veracidad de los hechos. En "El ministro suplente" [2013] se pasa de Kousbroek, maestro del artículo corto, a Ruiz-Gallardón y la ley del aborto para ridiculizar la misión de estos profesionales como si fueran suplentes y luego confluir en una primera persona fantasmal: "Recuerdo que me dije..." donde el yo textual afirma poder ser "científico, marmolista, boxeador, subastador, ojeador de futbolistas, ajedrecista, baturro, espía, bombero de aeródromo".

Los elementos deícticos de tipo semántico resultan a menudo también inespecíficos: "un país...", "un mundo...". Otras veces contienen referentes concretos, pero de los que se produce un alejamiento a través de analogías disparatadas. En "Estados de ánimo" [2012] revela cómo para Julien Gracq los detalles mínimos de una época ocultan lo importante, como unas niñas dando ramos a la virgen mientras estaba a punto de producirse la batalla de Rezonville. Dicho ejemplo le sirve de

\footnotetext{
${ }^{4}$ La cursiva es nuestra (se habían encerrado / acabábamos)
} 
entradilla para hablar de las palabras "rescate", "intervención", "prima de riesgo" propias de la España de la crisis, detalles que -afirma- pronto se olvidarán como esas niñas de Gracq. En "Teorías inciertas" [2015] relaciona diferentes orientaciones políticas de los escritores con "la relación de cada uno con los cordones de sus zapatos". La mención a Blanchot y a la desaparición de la literatura unifica el artículo "Ni siquiera estamos" [2016], que por otro lado finaliza haciendo la siguiente analogía: "como nuestro baldío Congreso de los Diputados, donde es difícil que pueda uno ahí sentirse vivo, ya no digamos representado."

Asimismo, lo neutral se conjuga con lo connotado de manera sorprendente. Bien encontramos referentes, fechas, títulos pero de repente desembocamos en un paraje de desbocadas hipérboles o brutales retahílas de adjetivos expresivos, como los siguientes: "un país de vociferantes en podios de cáscaras de gambas", , "futuros fangos ultraconservadores"6 En "Estado de ánimo" [2012] el adjetivo "fatídico" aparece cinco veces en un efecto de repetición y ampliación siempre orientado al hartazgo de lo español, que culmina en: "dibujo fatídico de nuestro adn nativo" o "nuestro fatídico adn de imbéciles rebotados". Dicho contraste estilístico e irónico refuerza la sensación de producto literario fruto del esfuerzo de la forma. Asimismo, lo hipotético y la aseveración conviven en un modo de enunciación inestable y donde los significados se precipitan como "un tapiz que se dispara en múltiples direcciones." ${ }^{\prime 7}$ En "Ideas para interrumpir" [2011] se parte de la duda: “¿Es la interrupción (...) un tema de la cultura contemporánea? No lo dudo. Pero hay ciertos misterios ahí por resolver" para después un final que roza la sentencia y el epifonema:

Tan inmersos nos hallamos en la realidad mediática que hasta nos olvidamos con frecuencia de que, si apagáramos de golpe la machacona mentira oficial, un mundo inédito podría estar aguardando al otro lado.

Por último, pudiéramos pensar que se trata de reflexiones solipsistas, pero la voluntad de comunicación con el lector puede garantizarse a través de no pocas apelaciones: "Por si alguien quiere escapar un rato de esa chata vía nacional, propongo que nos desviemos hacia el humor ${ }^{\prime \prime} \mathrm{O}$ interrogaciones retóricas: “¿Quién no recuerda a Joyce diciendo que ya que no podemos cambiar la realidad, cambiemos al menos de conversación?"”

\footnotetext{
5 "Viejas muecas" [2011].

6 "Después de la Revolución" [2016].

7 "Propuesta de cambio" [2016].

8 "Brod insulta a Brod" [2013].

9 "Conjuras invisibles" [2010].
} 


\section{El compromiso de la forma y de la mirada crítica}

Dichas estrategias de vehicular lo político a través de la ambigüedad no son casuales. Son prácticas que aparecen también en su obra narrativa y que ensanchan el yo textual anfibio, yo ejecutivo o yo figurado del texto [Pozuelo Yvancos 2005 y 2014]. Además, en diversos lugares hallamos artículos que funcionan como una declaración de principios al respecto. En un texto previo fundamental, antologado en múltiples ocasiones, "Mastroianni-sur-Mer", se había ya posicionado sobre "el compromiso de la literatura":

\footnotetext{
El compromiso en la literatura ha dado lugar a bastantes malas novelas. Y el compromiso ideológico, explícitamente ideológico, ha producido pésimas obras. La gracia de Sostiene Pereira es que es una impecable y formidable novela política sin ser en ningún momento un texto ideologizado. Creo compartir con Tabucchi mi mejor desconfianza para toda la literatura elaborada mediante una determinación ideológica. Otra cosa es comprometerse desde un punto de vista humano, contemplando la Historia como un enorme organismo, y dando gran importancia a la vertiente humana de la misma. [2000:195].
}

Más recientemente hemos podido leer "Sobre contenidos políticos" [2016], de Café Perec, donde ser un escritor "comprometido", o que asume una "responsabilidad social" queda ridiculizado como una manera de "verse mejor a sí mismo", y se denuncia la impostura que ello supone: "hay quienes hacen marketing de la buena conciencia política". En este sentido, acaba defendiendo lo político implícito o el sentido "inmanente a la forma" a la manera de Adorno, o siguiendo el legado de de Kafka: "Los sistemas políticos van sucediéndose, pero la literatura puede ir más allá sin renunciar a los problemas de su tiempo".

Estos microensayos de Vila-Matas, en fin, funcionan como un faro que advierte contra la aceptación sin más de ideas comunes; en paralelo a temas políticos, alertan contra la manipulación del mundo mediático y la tiranía de la imagen y sus falacias; en "Agitación en la Red" [2014] denuncia el riego de aborregamiento en la Red y aquellos "colectivos de cuervos que censuran a aquellos que se distancian de lo que mastica el vulgo" y previene sobre los peligros del imperio del "nosotros ante el yo" que convierte a algunos autores en "esclavos de una concepción distorsionada de la participación". Vila-Matas, en suma, arremete contra la uniformidad irreflexiva, la manipulación de las masas, la extensión de la ignorancia. En este sentido, retoma a Razones y osadías de Flaubert en dos artículos "Esperar trescientos años" [2011] y “Una estupidez formidable y universal" [2017]. Aquí 
emprende un obús contra la "dudosa claridad intelectual" que caracteriza no solo a las masas sino también a los gobernantes "la Estupidez" ha derivado en un "mal formidable y universal". La única solución, como rezaba Flaubert, es "Ilustrar a las clases ilustradas, esto es, a los políticos, a los que tilda de "mamarrachos". No parecemos aquí hallarnos lejos Ortega y Gasset de La rebelión de las masas cuando denunciaba al hombre-masa y el excesivo imperio de la vulgaridad, que a menudo era el especialista-bárbaro o el sabio-ignorante:

Lo característico del momento es que el alma vulgar, sabiéndose vulgar, tiene el denuedo de afirmar el derecho a la vulgaridad y lo impone dondequiera. [Ortega y Gasset 1996: 59].

\section{Vila-Matas, intelectual heterodoxo}

En resumidas cuentas, lejos de cualquier orientación política, Vila-Matas promueve el universo literario, el cultural, combatiendo la manipulación y la ignorancia. ¿Y no sería este el intelectual que describe Blanchot en los años ochenta, siguiendo la estela de Barthes? "El intelectual está tanto más cerca de la acción en general y del poder cuanto menos se mezcle en la acción y menos poder político ejerza" [2003: 56]; esto es, el intelectual debe mantenerse en un espacio literario y una neutralidad general, ha de estar "en la retaguardia de la política", "como un centinela que estuviera allí más que para vigilar, mantenerse despierto", "reflexiona unas veces, otras se calla"; "es incrédulo, duda, asiente cuando hace falta, no aclama" [2003: 56-57].

En el contexto hispánico, Vila-Matas coincidiría también con la generación posterior a la literatura de compromiso española y ciertos autores como Rafael Ferlosio o Juan Benet que, sin renunciar a la necesidad moral de la literatura, alertaban de los riesgos del "compromiso" como auto encasillamiento o que asociaban lo moral sobre todo a la forma de la escritura [Vila 2017: 149-151]. En este sentido, la escritura ensayística de la que hace gala Vila-Matas en "Café Perec" resulta representativa de este ensayismo contemporáneo como "escritura pensante o pensamiento que surge al impulso a la vez del estilo y de la realidad envolvente". [Gracia y Ródenas 2015:16], un ensayo que no se quiere redentorista y que participa de su función de llamamiento al lector con ironía y desapego y usando abundantes recursos literarios, tal y como ha venido siendo habitual desde los años 90: 
la búsqueda de formas del ensayo expresamente deudora de mecanismos literarios indisimulados, sean recursos narrativos, el ingenio retórico o verbal o la vía metafórica (...) como cauce de un pensamiento en marcha y a menudo poco conclusivo. [lbid: 254].

Ahora bien, no resulta casual tampoco que en el cambio de siglo y ante una situación política y social cada vez más crítica y bajo la sensación de latrocinio y de desconfianza respecto al propio estado, el escritor ha recrudecido sus armas de combate verbal, como hemos observado en numerosos de los artículos de Café Perec.

Volviendo a la pregunta inicial, ¿qué tipo de discurso intelectual supone el texto deVila-Matas y de qué manera se integra en el espacio público actual? Vila-Matas se trata de un autor consagrado, leído por una minoría consolidada, así que su voz está legitimada en el campo cultural actual, si bien no goce de una autonomía total respecto a sus condicionantes, como querían Said y Bourdieu, puesto que la editorial Seix Barral y el periódico El País garantizan su lugar en el mercado y en el discurso mediático; de este modo, el escritor-intelectual no se trata en este caso de un "outsider" ni un "francotirador" que actúe desde fuera del establishment [Said 1996] ${ }^{10}$.

En cuanto a la relación de Vila-Matas con la sociedad 2.0, se halla en una suerte de umbral entre la verticalidad del antiguo intelectual del siglo XX y la horizontalidad por la que circula el saber en el siglo XXI. Así, si bien la figura de Vila-Matas se construye desde el discurso intermedial' ${ }^{11}$, con múltiples apariciones en eventos, en instalaciones artísticas, y vehiculando su obra a través de su página Web, en transformación constante; por otro lado su discurso sigue un canal unidireccional, que es el del autor hacia el lector u oyente. Esto es, no participa de las redes sociales, ni posee cuenta de Twitter ni de Facebook. El café literario que él propone en sus artículos, pues, continúa siendo un émulo del café literario antiguo, el espacio para compartir entre unos pocos, con cierto feed-back pero normalmente diferido para el momento de la intimidad entre autor y lector. Está lejos, pues, de

\footnotetext{
${ }^{10}$ Para Bourdieu el intelectual no puede estar coartado ni por los mecanismos del poder ni por los medios de comunicación de masas. En Intelectuales, política y poder Bourdieu nos alerta de las dos amenazas que atentan contra dicha autonomía, el "mundo del dinero" y la "tecnocracia de la comunicación". Para afirmar: "Es en la autonomía más completa con respecto a todos los poderes, donde reside el único fundamento posible de un poder propiamente intelectual, intelectualmente genuino." Vila-Matas ha conseguido representar un concepto literario y ser vendido dentro de una editorial y tener una tribuna casi permanente en un periódico concreto que es El País. ¿Podría gozar de esa aura de credibilidad en sus artículos Café Perec si no estuviera respaldado por el beneplácito del mercado literario? Pero esa es otra cuestión que nos llevaría en otras direcciones.

11 Término definido entre otros por Eric Méchoulan, para quien la intermedialidad es una "hermenéutica de los soportes" o Amélie Florenchie, que define la "narrativa intermedial" como "una poética de la mediación que aporta una respuesta técnica, pero también estética y política, a la reflexión sobre las relaciones conflictivas entre los medios de información y comunicación, por un lado, y los valores sobre los que se funda la democracia, por otro" [Florénchie 2016: 55].
} 
un intelectual identificado con la inmediatez y el tú-a-tú como el e-intelectual definido por Minc [2012] o del "intelectual a golpe de tuit y pantallazo" del que ha hablado Jabois [2014].12

Respecto a la forja de su discurso, podríamos hablar de intelectual-artista, por cuanto la base discursiva no es la afirmación categórica sino la experimentación lingüística para dejar al desnudo la falacia de ciertos recursos de la sociedad de la información que nos plantean las verdades como únicas e irrefutables; ya Ricardo Piglia afirmó, a propósito de Chomsky:

un lingüista es por supuesto el que mejor percibe el escenario verbal de la tergiversación, la inversión,

el cambio de sentido, la manipulación y la construcción de la realidad que definen el mundo moderno

[Piglia 2015: 126].

El lugar del intelectual canónico ha quedado vacío hoy, asolado por la fuerza de los medios, de la especialización, la política y la publicidad, el presentismo y el neoliberalismo [Traverso 2013]. Ni siquiera los políticos leen "lo que dicen los intelectuales", como el mismo Vila-Matas ha denunciado recientemente, ${ }^{13} \mathrm{y}$ hasta la misma palabra se usa de modo despectivo. Sin embargo, tanto escritores como intelectuales actúan de manera indistinta "en la nueva esfera pública dominada por la globalización" [Said 2006: 155], en contextos en continua expansión, de modo que hoy en día podemos considerarlos de manera conjunta y tener en cuenta al unísono su función pública y "la esfera de un arte exigente", que es "el hogar provisional del intelectual" [lbid: 170]. O como indica Gerard Noirel: deberían trenzarse alianzas entre intelectuales y artistas para que el mensaje pueda superar el antiguo aristocracismo del pensamiento y mueva a la emoción [2012]. Ese camino parece haber iniciado Vila-Matas en sus artículos mestizos.

Por último, deberíamos precisar que la negación de una literatura comprometida en sentido ideológico no se relaciona necesariamente con una postura escapista. El escritor- intelectual puede estar muy comprometido de un modo moral, en su voluntad de pasar la contemporaneidad por el cedazo del pensamiento crítico para después llevar la utopía del arte a sus últimas consecuencias. ${ }^{14}$ Con sus estrategias discursivas, Vila-Matas logra en los artículos Café Perec desautomatizar los carriles habituales y desvelar el funcionamiento de las mentiras oficiales para acceder a una verdad relativa,

\footnotetext{
${ }^{12}$ ¿Es por ello su discurso menos representativo de los mecanismos democráticos? No creemos que deba ser así solo por rehuir el enfrentamiento huero en las redes sociales, y teniendo en cuenta que los textos e intervenciones de Vila-Matas sí son abiertos a todo público tanto en la página Web como en Youtube.

${ }^{13}$ Ver www.abc.es/cultura/libros/abci-vila-matas-sobre-cataluna-tenemos-cambiar-protagonistas-201710161644_noticia.html

${ }^{14}$ Said definía el intelectual precisamente como aquel que, a través de su uso particular del lenguaje, se esfuerza por "romper los estereotipos y las categorías reduccionistas que limitan el pensamiento y la comunicación humanos" y cuestiona "el nacionalismo patriótico, el pensamiento corporativo, y el sentimiento de superioridad clasista, racial o sexual" [1994: 12, 15].
} 
tan inestable como profundamente exigente. La subversión estética deviene en subversión política; al desmontar lo evidente, lo que nos viene dado como obvio: al literaturizar los temas políticos que vienen del texto mediático actual (subjetivándolos, asociándolos a analogías literarias, ironizándolos, hiperbolizándolos) estos pierden consistencia y se fusionan con el continuum del tejido literario intertextual universal. Y así se vuelven opinables, moldeables, dejan de constituir un discurso único compacto proclive a promover la manipulación del lector. ${ }^{15}$

\section{Conclusiones}

El Café Perec de Enrique Vila-Matas nos devuelve a una tertulia no vertical ni horizontal en la red, tal vez a un ensayo diagonal y también excéntrico, pero no por evasivo sino por heterodoxo: un espacio literario pero también político, donde el pensamiento avanza de forma lúdica y donde las asociaciones de ideas constituyen hallazgos tan valiosos como el encuentro fortuito entre un paraguas y una máquina de coser de los que hablaba Lautréamont.

En la textura ambigua del discurso que trenza literatura con realidad política, en la palestra que constituyen los artículos Café Perec desde la red se halla a nuestro entender una senda necesaria que todavía se puede transitar. La literatura, entendida como arma de inteligencia que promueva la desconfianza y el pensamiento complejo, puede servir aún de salvoconducto para sortear los abismos de la vida mediática.

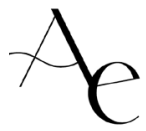

\footnotetext{
15 Podemos argüir con Schaeffer [2004] que los textos de origen factual revisten más peligro en la manipulación del lector que los textos literarios, porque, mientras la representación referencial convoca una "creencia" espontánea en el lector, la representación ficcional inspira como mucho una creencia construida, esto es, voluntaria, y se accede por ella a un terreno lúdico y compartido que no admite engaño.
} 


\section{BIBLIOGRAFÍA}

ARANDA, Alfredo: La escritura articulística y ensayística de Enrique Vila-Matas: la crítica de un escritor. Tesis defendida en la Universidad de Barcelona (Enero 2017). Consultable en el depósito UB http://diposit.ub.edu/dspace/handle/2445/107831.

BARTHES, Roland: Essais critiques. Oeuvres complètes, II. Paris: Seuil, 2002.

BENET, Juan: La inspiración y el estilo. Barcelona: Alfaguara, 1999.

BLANCHOT, Maurice: Los intelectuales en cuestión. Madrid: Tecnos, 2003.

BOURDIEU, Pierre: Intelectuales, política y poder. Madrid: Clave intelectual, 2012.

DOMÍNGUEZ MICHAEL, Christopher: "El príncipe de los shandys", en Margarita Heredia (ed.), VilaMatas portátil. Un escritor ante la crítica. Canet de Mar: Candaya, 2007, pp. 59-62.

FLORENCHIE, Amélie: "Narrativa intermedial y poética de la mediación”, en Gabriela Cordone y Victoria Béguelin-Argimón (eds.), Manifestaciones intermediales de la literatura hispánica en el siglo XXI. Madrid: Visor Libros, 2016, pp. 55 a 70.

GONZÁLEZ DE CANALES CARCERENY, Júlia: Releyendo a Enrique Vila-Matas. Placer e irritación. Barcelona: Anthropos, 2016.

GRACIA, Jordi: "Todo mentira", El País, 03/12/2015.

GRACIA, Jordi, RÓDENAS, Domingo: Pensar por ensayos en la España del siglo XX.

Bellaterra, Edicions UAB, 2015.

JABOIS, Manuel: "Intelectuales a golpe de tuit y pantallazo", tintaLibre, 17 (septiembre 2014), pp. $232-245$.

MARTí MONTERDE, Antoni: Poética del café: un espacio de la modernidad literaria europea. Barcelona: Anagrama, 2007.

MARTíNEZ DE PISÓN, Ignacio: “El notario de lo raro” en Margarita Heredia (ed.), Vila-Matas portátil. Un escritor ante la crítica. Canet de Mar: Candaya, 2007, pp. 239-241.

MINC, Alain: Una historia política de los intelectuales. Barcelona: Duomo, 2012.

NOIREL, Gérard: Dire la vérité au pouvoir. Les intellectuels en question. Marseille: Agone, 2010.

OHMANN, Richard: "El habla, la literatura y el espacio que media entre ambas", en José Antonio Mayoral (coord..), Pragmática de la comunicación literaria. Madrid: Arco / Libros, 1999, pp. 35-57. 
OÑORO OTERO, Cristina: Enrique Vila-Matas. Juegos, ficciones, silencios. Madrid: Visor, 2015.

ORTEGA Y GASSET, José: La rebelión de las masas. Santiago de Chile: Andrés Bello, 1996.

PIGLIA, Ricardo: Antología personal. Barcelona: Anagrama, 2015.

POZUELO YVANCOS, José María: “El género literario 'Ensayo'" en Vicente Cervera, Belén Hernández y Ma Dolores Adsuar (eds.), El ensayo como género literario. Murcia: Universidad de Murcia, 2005.

__ Figuraciones de yo en la narrativa: Javier Marías y Enrique Vila-Matas. Valladolid: Universidad de Valladolid, 2014

__ "Vila-Matas y el arte de contar", ABC Cultural, 25/02/2017.

SAID, Edward: Representaciones del intelectual. Barcelona: Paidós, 1996.

—_ La responsabilidad pública de escritores e intelectuales. Barcelona: Debate, 2006.

SALDAÑA, Alfredo: "Sobre literatura y nacionalismo cultural", en Túa Blesa, Juan Carlos Pueo, Alfredo Saldaña y Enric Sullà (coord.), Pensamiento literario español del siglo XX, 6. Zaragoza: Tropelías, 2012. Pp. 189-201.

SARTRE, Jean-Paul: ¿Qué es la literatura? Buenos Aires: Losada, 2008.

SCHAEFFER, Jean Marie: «Fiction et croyance» en Natahlie Heinich \& Jean-Marie Schaeffer (coor.), Art, création, fiction. Nîmes: Jacqueline Chambon, 2004.

TRAVERSO, Enzo: Où sont passés les intellectuels? Paris: Textuel, 2013.

VILA, José-Antonio: "Los intelectuales, el compromiso y el medio siglo español". Artes del ensayo, 1 (2017) pp. 140 a 152.

VILA-MATAS, Enrique: "Ha llegado la imaginación", Fotogramas, XXIII, 1054, 27/12/1968. P. 18.

__, "Mastroanni-sur-Mer", en Desde la ciudad nerviosa. Madrid: Alfaguara, 2000. Pp. 171-208.

—, "La gallina robada (Cuento de Navidad)", en El traje de los domingos. Madrid: Huerga y Fierro, 2006. Pp. 13-14.

__ , "Espiando a los artistas", en El traje de los domingos. Madrid: Huerga y Fierro, 2006. Pp. 23-28.

—_, "Café Perec", El País, 24/05/2008.

__, "Conjuras invisibles", El País, 01/06/2010.

__ "Si no fuera por la crisis", El País, 18/01/2011.

__ , "Ideas para interrumpir", El País, 15/03/2011.

__, "Esperar trescientos años", El País, 21/06/2011.

__, "Viejas muecas", El País, 27/12/2011. 
——, "Estado de ánimo", El País, 12/06/2012.

—_, "Acuérdate de desconfiar", El País, 01/07/2012.

—_, "Del amor", El País, 25/09/2012.

— , "El gran fracasista", El País, 11/12/2012.

__, "Nuestra salvación", El País, 05/02/2013.

__, "Brod insulta a Brod", El País, 05/03/2013.

__, "Dirección animal", El País, 28/05/2013.

_ , "Propuesta de cambio", El País, 19/11/2013.

—_, "El ministro suplente", El País, 31/12/2013.

—_, "La noche de Europa", El País, 08/04/2014.

__, "Agitación en la Red", El País, 17/06/2014.

—_, "Teorías inciertas", El País, 12/05/2015.

__, "La manía de caernos del mundo", El País, 21/07/2015.

—_, "Sobre contenidos políticos", El País, 02/02/2016.

__, "Súbita aparición de Nunes", El País, 19/07/2016.

__, "Ni siquiera estamos", El País, 19/09/2016.

—_, "Después de la Revolución”, El País, 14/11/2016.

__, "Una estupidez formidable y universal", El País, 4/04/2017.

__ "Encerrados con un solo tedio", El País, 13/06/2017

__, "35 años de Glenn Gould", El País, 03/10/2017.

__, "Viaje a Bastia", El País, 16/10/2017.

__ "Tenemos que cambiar a los protagonistas, el diálogo es necesario" (ABC Cultura, 16/10/2017. 